\title{
IMPLEMENTATION OF METHOD OF DESIGN OF EXPERIMENT INTO PROCESS OF RECOMMENDATION OF LIQUIDUS AND SOLIDUS TEMPERATURES OF INGOT CAST STEEL GRADES
}

\author{
${ }^{1}$ Michaela STROUHALOVÁ, ${ }^{2}$ Karel GRYC, ${ }^{1}$ Bedřich SMETANA, ${ }^{1}$ Karel MICHALEK \\ 1VSB - Technical University of Ostrava, Czech Republic, EU, michaela.strouhalova@vsb.cz \\ ${ }^{2}$ The Institute of Technology and Business in České Budějovice, Faculty of Technology, Czech Republic, EU, \\ gryc@mail.vstecb.cz
}

https://doi.org/10.37904/metal.2019.795

\begin{abstract}
The vast majority of metals and alloys used in technical practice are produced from a liquid state - a liquid metal. A most important phase transformation at steelmaking process is crystallization of steel (phase transformation of liquid steel from liquid to solid state) and process of own solidification of steel. This paper deals with study of phase transformations in steel during its solidification process. Specifically, it is focused on possibility of experimental refinement of liquidus $\left(T_{L}\right)$ and solidus $\left(T_{S}\right)$ temperatures of real industrially produced steel grades cast into mould by the direct thermal analysis method. Experimental study of steel solidification process is one of the ways to eliminate their possible impacts on quality of cast steel during solidification and to achieve required properties of steel without any additional treatment. Dozens of ingot steel grades by direct thermal analysis method on Netzsch STA 449 F3 Jupiter experimental system were analysed. A series of methodological experiments on pure nickel standard metal in order to generate a methodology of direct thermal analysis methods to study real steel grades and identification of the influence of selected experimental conditions were performed. Practical implementation of the Design of Experiment method (DOE) to system of evaluation of correctness of measured data was also realized. Comparison of the results of the parallel methods used for $T_{L}$ and $T_{S}$ identification was also performed. A result of the whole process of refinement of $T_{L}$ and $T_{S}$ temperatures represents a final recommendation of one proper $T_{L}$ and $T_{S}$ temperature of each studied steel grade.
\end{abstract}

Keywords: Steel, ingot solidification, thermal analysis, design of experiment, thermodynamic software

\section{INTRODUCTION}

Nowadays, experimental work carried out outside the virtual space of powerful computer stations re-gain in importance again. These virtual systems should be supplied by real experimentally proven and verified data. Only in this way they can generate important findings. Even the most sophisticated software is able to generate the wrong (harmful) result due to incorrect setting of boundary conditions. By all these reasons, practical measurements in some areas, improvement of production processes is still irreplaceable.

That's why the implementation of method DOE to get the correctly defined liquidus $\left(T_{L}\right)$ and solidus $\left(T_{S}\right)$ temperatures into industrial applications (conditions) is solved in the context of this study. Not only in relation with numerical simulations [1,2], where the desired result is due to correctly set of width of two-phase region or from the perspective to setting of steel casting process, that $T_{L}$ is important for superheat setting of the steel before casting at the end of secondary processing of steel [3-15]. The accurately defined $T_{L}$ and $T_{S}$ temperatures into both the mentioned have the crucial significance for increasing the efficiency and quality of production of continuous cast, as well as ingot cast steel.

The paper presents combination of the DOE (Design of Experiments) and DirTA (direct thermal analysis method) applications. The results of own DirTA measurements (experimentally determined $T_{L}$ and $T_{S}$ temperatures) of group of a number of steel grades cast into moulds were processed using the statistical 
method of the planned experiment (DOE) for the purpose of evaluation of relevance (correctness) of these experimentally determined $T_{L}$ and $T_{S}$ and subsequent recommendation of $T L$ and $T_{s}$ temperatures of these ingot cast steel grades to operating conditions.

For this purpose, dozens steel grades cast into the moulds by the DirTA method were measured and the temperatures of liquidus and solidus on experimental background of analysis [16] were determined. In accordance to European standards and API standards, these types of ingot steel grades were analysed: samples from steel ingots used in conditions of processing of forgings (thick steel plates, blocks, pads, bars designed for special machine engineering elements from tool steel, bearing steel).

With regard to the limited possibilities of publishing a large number of obtained results, the article primarily contributes to the explanation of the principle of using / application the DOE method in the context of recommending final $T_{L}$ and $T_{s}$ for individual ingot cast steel grades. Attention will not be devoted to discussing specific final recommended $T_{L}$ and $T_{S}$ temperatures for the studied ingot steel grades.

\section{GENERAL IDEA OF DOE IMPLEMENTATION INTO PROCESS OF RECOMMENDATION OF LIQUIDUS AND SOLIDUS TEMPERATURES}

Method DOE (Design of Experiments) $[17,18]$ is defined as the systematic procedure carried out under controlled conditions in order to discover an unknown effect, to test or establish a hypothesis, or to illustrate a known effect of experimental parameters those are crucial during DirTA process. Design optimization of experiment is often used to evaluate which process inputs (selected factors) have a significant impact on the process output parameters (responses), and what the target level of those inputs should be to achieve a desired result (output). Experiment can be designed in many different ways to collect these information and testing at various levels.

Standard output of the experimental design of selected combination of input factors is an optimized mathematical model and principally regression equations to find a level of factors whose allow reaching (finding) the optimum value of the monitored response in which maximum resolution can be achieved for the statistical significance of factors and their interaction. Undeniable advantage of DOE application is option to get as much information as possible about the model behaviour using a small number of observations as possible.

In the context of this study the application of DOE wasn't used to acquire a model for liquidus and solidus temperatures determination, but to use the advantage of a correctly set experimental plan to statistically evaluate the statistical significance of critical experimental factors (regime of experimental mode, use sequences in DirTA experiments) on the quality of measured data ( $\left.T_{L}, T_{S}\right)$. Expected outcomes of DOE approach is identification of the statistical significance of these factors due to whose it will be possible to standardize the process of own evaluation of experimentally determined $T_{L}$ and $T_{S}$ from DirTA as well as capture the current course (run) of the experiments of each analysed ingot cast steel grade.

Temperature mode is one of the elementary standard experimental conditions that have an unambiguous influence on the value of phase transformation temperature $[19,20]$. The involvement of two cycles to DirTA experiments in an effort to increase the number of values (evaluable data) that can be obtained from the temperature curves within one analysis of the steel sample were carried out. Because the number of each analysed steel samples is generally limited (with regard to economic requirements) to 2, max. 3 pieces.

This adjustment of DirTA experiment allowed to obtain overall 4 values of $T_{L}$ and $T_{S}$ based on one DirTA analysis, yet. Thought realization of 2 experimental DirTA measurements of each studied ingot steel grade an 8 value of $T_{L}$ and $T_{S}$ is possible to achieve.

Even with a relatively small number of experiments, the aim is to find out which $T_{L}$, resp. $T_{S}$ can be used to calculate one relevant / proper liquidus and solidus temperature for studied steel grade. From a practical point 
of view, based on the DOE results, it is possible to make a qualified decision, whose of all experimentally determined $T L$, resp. Ts temperatures from dirTA experiment can be used for the calculation of one mean $T L$, resp. Ts value without distinguishing between the temperature of linear heating and cooling mode or cycle, or whether the $T_{L}$, resp. $T_{S}$ determined under the linear heating and cooling conditions need to be evaluated separately or whether the cycles are statistically significantly different from the first cycle and therefore it isn't possible to determine the one mean $T_{L}$ or $T_{S}$ must to be calculated with respect to belong to each cycle from which the $T_{L}$ or $T_{S}$ were determined.

According to the current procedure (previously process) of choice relevant $T_{L}$ and $T_{S}$ temperatures at the process of their averaging and determination of the mean value of these phase transformation temperatures was respected a type of temperature mode (heating $x$ cooling), but the possible effect of involvement of second cycle, wasn't respected yet, although its possible influence was discussed. This effect has not been clearly proved. Thus, final $T L$ and $T s$ temperatures with the respect to temperature regime (that means a resolution between heating a cooling mode), but without the both cycles resolution, were calculated. DOE can be expected to be able to generate a correct and clear approach to how to work with individual experimental data at the process of the choice relevant $T_{L}$ and $T_{S}$ temperatures for each studied ingot steel grade. A detailed practical example of this DOE implementation is presented in the text below.

\section{CONSTRUCTION OF DOE DESIGN ON INGOTS CAST STEEL GRADES}

Design of Experiment (DOE) in all its successive applications, in accordance with relevant principles of statistical data analysis, was chosen in principle analogous applications widely used as a full factorial design realized at two levels of selected factors. Statistical significance of all above defined factors is tested at a significance level $\alpha=0.05$ for a confidence level of $95 \%$ in STATGRAPHIC Plus software through the $P$-value that indicates their statistical significance. The critical significance value is 0.05 . If the P-value effect is less than the critical significance value (i.e. 0.05), the effect of the observed factor is statistically significant. As the model captures the individual data, the R-squared value (adjusted to degree of freedom) tells us the precision of the chosen model.

\subsection{An overview of the studied factors}

The planned experiment DOE to identification of the statistical significance of effects of these selected factors on defined responses ( $T_{L}$ and $T_{S}$ ) were designed:

- $\quad$ statistical significance of the experimental mode influence (linear heating / linear cooling conditions),

- $\quad$ statistical significance of the influence of the using the sequences in DirTA experiments.

The significance of these studied factors $(R, S)$ influencing defined responses ( $T_{L}$ or $T_{S}$ ) on lower and upper level of studied factors were by DOE detected (Table 1 ).

Table 1 Overview of the factors and levels used for DOE construction

\begin{tabular}{|l|c|c|c|}
\hline \multicolumn{1}{|c|}{ Factor } & Mark of factor & Lower level & Upper level \\
\hline Regime of experimental mode & $\mathrm{R}$ & linear heating (H) & linear cooling (C) \\
\hline Turn of sequence & $\mathrm{S}$ & 1st cycle (1.) & 2nd cycle (2.) \\
\hline
\end{tabular}

Experimental mode (regime / type of experimental mode) is represented by these type factors levels:

- lower level of the factor indicating the temperature type of experimental mode represents linear heating mode $(\mathrm{H})$ and the upper level rationally represents linear cooling mode $(\mathrm{C})$,

- $\quad$ turn of sequence is represented by 1 st cycle of experiment run as lower level and by 2nd cycle of experiment run as upper level of studied factor. 


\subsection{Experimental DOE plan design}

Based on definition of the factors and their lower and upper levels, with the use categorical description of the variables (factors), a full factorial design experiment on two-levels, for all combinations (variation 1-4) of $R$ and S, for 2 relevant DirTA experiments (2 steel samples), was designed (Table 2).

Table 2 Proposed DOE experimental design for all studied ingot steel samples

\begin{tabular}{|c|c|c|c|c|c|}
\hline \multirow{3}{*}{$\begin{array}{c}\text { Variation } \\
1 \\
\end{array}$} & \multicolumn{2}{|c|}{ Factor } & \multirow{2}{*}{\multicolumn{2}{|c|}{$\begin{array}{l}\text { Number of DirTA measurements } \\
\text { of each ingot steel sample }\end{array}$}} & \multirow{3}{*}{$\begin{array}{l}\text { Response } \\
T_{L} \text { resp. } T_{S}\end{array}$} \\
\hline & \multirow{2}{*}{$\begin{array}{l}\mathbf{R} \\
\mathrm{H} \\
\end{array}$} & \multirow{2}{*}{$\mathbf{S}$} & & & \\
\hline & & & $1 \mathrm{st}$ & 2nd & \\
\hline 2 & C & $1 \mathrm{st}$ & $1 \mathrm{st}$ & 2nd & $T_{L}$ resp. $T_{S}$ \\
\hline 3 & $\mathrm{H}$ & 2nd & $1 \mathrm{st}$ & 2nd & $T_{L}$ resp. $T_{S}$ \\
\hline 4 & C & $2 n d$ & $1 \mathrm{st}$ & 2nd & $T_{L}$ resp. $T_{S}$ \\
\hline
\end{tabular}

\section{DISCUSSION OF THE PRINCIPLE OF DOE APPLICATION INTO PROCESS OF DATA EVALUATION}

Chosen factors (regime of experimental mode, turn of sequence) were tested for statistical significance for each of their effects for 2 selected ingot steel grades $A$ and $B$ (Table 3 ).

Table 3 Estimated effects of the statistical significance of temperature regime of experimental mode and sequences in the DirTA experiments on the $T_{L}$ and $T_{S}$ temperature of 2 selected ingot steel grades

\begin{tabular}{|c|c|c|c|c|c|}
\hline \multirow[b]{2}{*}{ Steel grade } & \multirow[b]{2}{*}{ Response } & \multicolumn{3}{|c|}{ Statistical significance of studied factors } & \multirow{2}{*}{$\begin{array}{c}\text { R-squared } \\
\text { adjusted value }\end{array}$} \\
\hline & & $\begin{array}{c}\text { Temperature } \\
\text { mode }\end{array}$ & Cycle & Interaction & \\
\hline \multirow{2}{*}{ A } & $T_{L}$ & Yes & No & No & $99 \%$ \\
\hline & $\mathrm{T}_{\mathrm{S}}$ & Yes & Yes & Yes & $99 \%$ \\
\hline \multirow{2}{*}{$\mathrm{B}$} & $T_{L}$ & Yes & No & No & $93 \%$ \\
\hline & $\mathrm{T}_{\mathrm{S}}$ & No & No & No & $34 \%$ \\
\hline
\end{tabular}

According to Table 3 and evaluation the statistical significance of the temperature regime of experimental mode and use the sequences in the DirTA experiments on $T L$ temperature for steel grade $A, 1$ effect (temperature mode) has a $\mathrm{P}$ value of less than 0.05 , meaning that they are significantly different from zero at the $95 \%$ confidence level. DOE design for Ts the statistical significance effects of all studied factors detects. The conclusion for steel B are as follows - for TL was detected statistical significance of temperature mode, for $T_{S}$ the statistical significance of any of studied factors has not be identified.

Practical utility of DOE implementation into process of recommendation of liquidus and solidus temperatures of selected ingot cast steel grades A and B according to Tables $\mathbf{4}$ and $\mathbf{5}$ were explained.

Table 4 Procedure of calculation $T_{L}$ and $T_{s}$ temperatures based on DOE approach for ingot steel grade $A$

\begin{tabular}{|c|c|c|c|c|c|c|c|c|}
\hline \multirow{3}{*}{$\begin{array}{c}\text { Phase transformation } \\
\text { Temperature mode } \\
\text { Cycle }\end{array}$} & \multicolumn{4}{|c|}{ Liquidus temperature $\left(\mathrm{T}_{\mathrm{L}}\right)\left({ }^{\circ} \mathrm{C}\right)$} & \multicolumn{4}{|c|}{ Solidus temperature $(\mathrm{Ts})\left({ }^{\circ} \mathrm{C}\right)$} \\
\hline & \multicolumn{2}{|c|}{ Linear heating } & \multicolumn{2}{|c|}{ Linear cooling } & \multicolumn{2}{|c|}{ Linear heating } & \multicolumn{2}{|c|}{ Linear cooling } \\
\hline & 1st & 2nd & 1st & 2nd & 1st & 2nd* & 1st & 2nd* \\
\hline Sample 1 & 1486.3 & 1487.0 & 1482.3 & 1481.2 & 1411.1 & - & 1442.4 & - \\
\hline Sample 2 & 1486.6 & 1486.9 & 1482.5 & 1482.1 & 1409.8 & - & 1438.3 & - \\
\hline Mean value & \multicolumn{2}{|c|}{1486.7} & \multicolumn{2}{|c|}{1482.0} & 1410.5 & - & 1440.4 & - \\
\hline
\end{tabular}

* The values from 2nd cycle to be added to the table only if the statistical significance of cycle by DOE wasn't found. Otherwise, it can be assumed that values from 2 nd cycle are different from a data group from 1st cycle and cannot be included in mean value calculation. 
Based on estimated effects of statistical significance of studied factors (Table 3) on $T L$ temperature of steel grade $A$ a generally assumed conclusion on the suitability of a previous decision about temperature mode resolution was confirmed. Statistical significance of cycle and eventual interaction between studied factors of A steel grade, of this series of steel samples and of this group of $T_{L}$ values wasn't identified by DOE. With respect of the defined approach to determining relevant $T_{L}$ temperatures, based on testing of the statistical significance of the estimated effect of that factors (Table 3 ), into process of calculation of the mean $T L$ value (1 $T_{L}$ from linear heating, 1 $T_{L}$ from cooling mode) and also obtained from both cycles will be included (Table 4).

Table 4 shows that not only the regime of temperature mode, but also obviously the cycle has a statistically significant effect on the experimentally determined Ts values especially of this steel grade A. Therefore at the process of calculation of mean $T_{s}$ values it is necessary to respect which $T_{s}$ values belong to which temperature mode and also to remove (exclude) Ts values achieved at the second cycle of DirTA experiment, because it is evident, that between the 1 st and 2 nd cycle some change in own steel material has happened. This fact precisely illustrated, that $T$ s values determined from the 1st cycle are statistically different in comparison with $T_{s}$ temperatures determined in the 2 nd cycle. Therefore for steel grade A were achieved 2 mean $T_{s}$ values ( $1 \mathrm{~T}_{s}$ from linear heating mode, $1 \mathrm{~T}_{s}$ from linear cooling mode), while $\mathrm{T}_{s}$ temperatures obtained in 2nd cycle will not be included due to their exclusion by applying the DOE model from the process of the calculating of relevant Ts mean values (Table 4).

Based on the realization of DOE and statistical significance identification of the studied factors (Table 3 ), these $2 T_{L}$ and $2 T_{S}$ temperatures (Table 5) were for grade of steel B calculated and then included in the process of further comparison with parallel used TA method and to process of recommendation of one proper $T_{L}$ and $T_{S}$ temperature of this steel grade.

Table 5 Procedure of calculation $T_{L}$ and $T_{S}$ temperatures based on DOE approach for ingot steel grade $B$

\begin{tabular}{|c|c|c|c|c|c|c|c|c|}
\hline Phase transformation & \multicolumn{4}{|c|}{ Liquidus temperature $\left(T_{L}\right)\left({ }^{\circ} \mathrm{C}\right)$} & \multicolumn{4}{|c|}{ Solidus temperature $\left(\mathrm{T}_{\mathrm{s}}\right)\left({ }^{\circ} \mathrm{C}\right)$} \\
\hline Temperature mode & \multicolumn{2}{|c|}{ Linear heating } & \multicolumn{2}{|c|}{ Linear cooling } & \multicolumn{2}{|c|}{ Linear heating } & \multicolumn{2}{|c|}{ Linear cooling } \\
\hline Cycle & $1 \mathrm{st}$ & 2nd & 1st & 2nd & 1st & 2nd & 1st & 2nd \\
\hline Sample 1 & 1451.5 & 1451.0 & 1433.1 & 1439.2 & 1357.0 & 1453.0 & 1399.7 & 1421.1 \\
\hline Sample 2 & 1450.8 & 1456.3 & 1439.4 & 1439.3 & 1316.4 & 1314.0 & 1417.7 & 1418.1 \\
\hline Mean value & \multicolumn{2}{|c|}{1452.4} & \multicolumn{2}{|c|}{1437.8} & \multicolumn{4}{|c|}{1387.1} \\
\hline
\end{tabular}

In the case of Ts temperature of steel grade B, no significance by DOE in any of the factors studied was identified (Table 3). The example of this steel due to its Ts demonstrates the advantage of definitely clear identification of the statistically significant effect of temperature mode and cycle on the experimentally determined values of this phase transformation temperature.

Now, in the case of the $T_{S}$ temperature (in general, of course, also for $\mathrm{T}_{\mathrm{L}}$ ), in addition to the objectification of the DOE approach, it is also benefit that the DOE application can lead to a reduction of the calculated mean values (Table 5) and to prevent the calculation based on wrong values due to changes in material during thermo-analytical process. Within a limited number of measured values, the number of data increases to one value, which is also very positive from the point of view of value relevance.

Generally, if no statistical significance of any of the studied factors is demonstrated, the calculation of the relevant $T_{L}$ and $T_{S}$ temperatures is done without any distinction between temperature mode and cycles (sequences). The result will therefore be only one $T_{L}$ and one $T_{S}$, respectively (Table 5). 


\section{CONCLUSION}

The method of planned experiment DOE was applied to analyse the impact of two of the practical aspects (critical factors): the effect of different temperature modes (heating vs. cooling) and use the sequences (second cycle) in direct TA experiments on studied responses (i.e. $T_{L}$ and $T_{S}$ temperatures) by the specially designed plan of DOE for $T_{L}$ and $T_{S}$. To final quantification of relevant $T_{L}$, resp. $T_{S}$ temperatures for studied steel grade on basis of the result of the test of statistical significance testing by DOE only values that belong to the identical data file were included.

If the temperature mode statistically significant the $T L$, resp. Ts values belong to another data file and it is necessary to calculate the mean value of $T L$, resp. $T_{S}$ separately for each temperature mode. If the cycle identified to be statistically significant, it is not possible to include to the calculation of the mean value $T L$, resp. Ts the temperatures from this second cycle. There is a presumption that these values have been affected by changes of the measurement parameters, e.g.: change of the chemical composition of the material during the experiment, change of the sample contact with the crucible after the first re-melting, or based on other unknown changes during thermo-analytical process.

DOE is the simply and very effective way to identify the statistical significance of key effects of factors and to refine them more accurately moreover without time and additional financial demanding and large material analysis and without the use the large data file and work with data. DOE enables to work with data, which have technological context corresponding with studied purpose and methodological background. Knowledge of the studied system and conditions, which is reflected in the designed plan of DOE, replaces the otherwise required a large amount of measurements (data) for the realization of integrated statistical analysis and makes this execute even if there is a small data file (experimental results).

DOE in this application allows to find relevant data for the final calculation of liquidus and solidus temperatures more accurately than ever before. This is a fundamental role of the DOE application in relation to determining and recommending one proper liquidus and solidus temperature into real industrial practice conditions. Relevant $T_{L}$ and $T_{S}$ temperatures (from Tables 4 and 5 ) are afterward used at the process of final recommendation of $T_{L}$ and $T_{S}$ into industrial practice. Into industrial practise conditions were recommended final $T_{L}$ and $T_{S}$ choices from the comparison with $T_{L}$ and $T_{S}$ determined by parallel used DTA method (Differential Thermal Analysis) [21-23].

From these two methods of thermal analysis was finally recommended a value that is the least critical in relation to negative impact on the process of their implementation into steel casting technology. As the final temperatures (one proper) $T_{L}$, resp. $T_{S}$ of each steel grade a highest experimentally determined $T_{L}$ and lowest experimentally determined Ts was recommended [24].

\section{ACKNOWLEDGEMENTS}

This work was carried out in the financial support of the project of "Student Grant Competition" numbers SP2019/148 and SP2019/43.

This research work was created in the frame of the project TA0410035 "The research and development of an advanced production technology of the production and processing of tool steels for forgings for special components with higher added value".

\section{REFERENCES}

[1] SVIŽELOVÁ, J., TKADLEČKOVÁ, M., MICHALEK, K. Research of steel ingot casting and solidification using numerical modelling. In METAL 2018: 27th International Conference on Metallurgy and Materials. Ostrava: TANGER, 2018, pp. 192-198. 
[2] ZHANG, Q., WANG, X. Numerical simulation of influence of casting speed variation on surface fluctuation of molten steel in mold. Journal of Iron and Steel Research, International. 2010. vol. 17, no. 8, pp. 15-19.

[3] FLEMINGS, M. C. Solidification Processing. Metallurgical Transactions B. 1974. vol. 5, no. 10, pp. 2121-2134.

[4] JONŠTA, P., SUŠOVSKÝ, M., CARBOL, Z. et al. Improving of heats' thermal properties in the production of tool steels in electric arc furnace and during their secondary metallurgy processing. In METAL 2016: 25th International Conference on Metallurgy and Materials. Ostrava: TANGER, 2016, pp. 173-178.

[5] KOLEŽNIK, M., NAGODE. A., KLANCNIK, G. et al. Effects of solidification parameters on the micro- and macrostructure of the X19CrMoVNbN11-1 steel. Materiali in Tehnologije. 2013. vol. 47, no. 6, pp. 739-744.

[6] SCHWEINICHEN, von P., CHEN, Z., SENK, D. et al. Effect of different casting parameters on the cleanliness of high manganese steel ingots compared to high carbon steel. Metallurgical and Materials Transactions A. 2013. vol. 44 , no. 12 , pp. 5416-5423.

[7] BRIMACOMBE, J. K. Empowerment with knowledge - toward the intelligent mold for the continuous casting of steel billets. Metallurgical Transactions B. 1993. vol. 24, no. 6, pp. 917-935.

[8] SHIRAIWA, T., SAKAMOTO, Y., KOBAYASHI, S. et al. Automatic control of casting speed in ingot casting. Automatica. 1981. vol. 17, no. 4, pp. 613-618.

[9] GHOSH. A. Segregation in cast products. SÄDHANÄ. 2001, vol. 26, pp. 5-24.

[10] LI. J., WU, M., ANDREAS, L. et al. Simulation of macrosegregation in a 2.45-ton steel ingot using a three-phase mixed columnar-equiaxed model. International Journal of Heat and Mass Transfer. 2014. vol. 72, pp. 668 - 679.

[11] HONGWEI, L., PAIXIAN, F., XIUHONG, K. et al. Formation mechanism of shrinkage and large inclusions of a $70 \mathrm{t}$ 12Cr2Mo1 heavy steel ingot. Research \& Development. 2014. vol. 1, no. 1, pp. 46-51.

[12] TASHIRO, K., WATANABE, S., KITAGAVA, I. et al. Influence of mould design on the solidification and soundness of heavy forging ingots. Transaction ISIJ. 1983, vol. 23, no. 4, pp. 312-321.

[13] ZYUBAN, N. A., RUTSKII, D. V., GAMANYUK, S. et al. Study of the crystallization of large forging ingots with a reconfigured bottom part. Metallurgist. 2012. vol. 56, no. 7/8, pp. 504 -509.

[14] DUB, V. S.; ROMASHKIN, A. N.; MAL'GINOV, A. N. Main trends in the development of technology for casting steel into ingots. Metallurgist. 2013. vol. 57, no. 5, pp. 487-504.

[15] BANDA, W., GEORGALLI, G. A., LANG, C. B. et al. Liquidus Temperature Determination of the Fe-Co-Cu System in the Fe-rich Corner by Thermal Analysis. Journal of Alloys and Compounds. 2008, Vol. 461, no. 1/2, pp. 178-182.

[16] GRYC, Karel., STROUHALOVÁ, Michaela, SMETANA, Bedřich et al. Determination of solidus and liquidus temperatures for bearing steel by thermal analysis methods. Metalurgija. 2017. vol. 56, no. 3-4, pp. 385-388.

[17] KUEHL, O. Robert. Design of Experiments: Statistical Principles of Research Design and Analysis. 2nd ed. Belmont, California: Brooks/Cole, 2000. 666 p.

[18] MONTGOMERY, C. Douglas- Design and Analysis of Experiments. 5th ed. USA: John Wiley \& Sons, Ltd., 2001. $684 \mathrm{p}$.

[19] GRYC, Karel, STROUHALOVÁ, Michaela, SMETANA, B. et al. Influence of direct thermal analysis experimental conditions on determination of the high temperature phase transformation temperature. Archives of metallurgy and materials. 2015. vol. 60, no. 4, pp. 2867-2871.

[20] STEFANESCU, D. M. Thermal analysis theory and applications in metalcasting. International Journal of Metalcasting. 2015, Vol. 9, no. 1. pp. 7-22.

[21] BOettinger, W. J., KATTNER, U. R., MOON, K. and PEREPECZKO, J. H. DTA and Heat-flux DSC Measurements of Alloy Melting and Freezing. Special Publication 960-15. Washington : National Institute of Standards and Technology, 2006. 90 p.

[22] HATAKEYAMA, T. and ZHENHAI, L. Handbook of thermal analysis. U.K. : Wiley, 1998. 452 p.

[23] BROWN, M., E. Handbook of Thermal Analysis and Calorimetry. Volume 1. Amsterodam : Elsevier, 1998. 722 p.

[24] STROUHALOVÁ, Michaela. Studium fázových změn v oceli během jejího tuhnutí. Doctoral Thesis. Department of Metalurgy and Foundry. Faculty of materials science and technology. VŠB-TU Ostrava, 2018. 